\title{
New tool will help civil engineers meet CDM requirements to design for safety
}

\author{
A new tool is being developed to help civil engineers and other construction professionals \\ improve their capability to design for safety under the Construction (Design and Management) \\ Regulations. Patrick Manu and Lamine Mahdjoubi of the University of the West of England, \\ Alistair Gibb of Loughborough University and Michael Behm of East Carolina University report.
}

In the UK over the past decade, the construction sector has consistently accounted for a greater proportion of the number of occupational fatalities, injuries and illnesses (HSE, 2015a).

While there have been many occupational safety and health improvements in the industry over recent years, the persistent and often tragic accidents are a constant reminder that sustained effort is still needed to keep driving down the number of injuries and illnesses in the sector.

Among the array of mechanisms for improving occupational health and safety, regulatory influence can be a powerful stimulus for improvement. In the UK, one of the prominent occupational health and safety regulations for the construction sector is the Construction (Design and Management) Regulations 2015 (HMG, 2015) - the 'CDM Regulations' (HSE, 2015b).

\section{Design for safety}

Studies in the UK and other countries have confirmed the link between design and the occurrence of accidents and injuries in construction (Behm, 2005; Gibb et al., 2006; Manu et al., 2014). As a result there is a growing importance for designers to consider the occupational health and safety implications of their design. This is generally referred to as 'design for safety' or 'safety in design'.

In the UK, design for safety has been prominent since the introduction of the CDM Regulations in the mid-1990s. While there are a number of changes in the 2015 regulations, fundamentally designers are still required to seek to mitigate occupational health and safety risk through their designs. CDM 2015 requires that the designer preparing or modifying designs should seek to eliminate, reduce or control foreseeable risks that may arise during the construction, maintenance and use of built assets.

\section{Organisational capability}

Additionally, organisations with design responsibilities are expected to have the appropriate organisational capability to carry out their design role in a way that secures occupational health and safety. This could be termed 'organisational design for safety capability', and those appointing design organisations also ought to ensure that this capability is appropriate for the project.

However, there is a lack of clarity regarding what constitutes organisational design for safety capability. There is therefore an urgent need for research in the built environment sector to address this gap. This is not only important from the standpoint of fulfilling CDM 2015 requirements, but more so from an organisational continuous process improvement perspective.

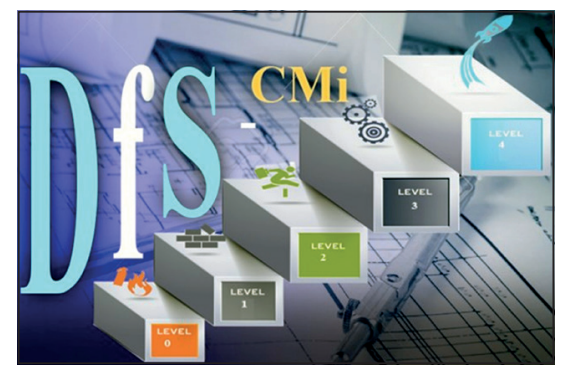

The design for safety tool currently being researched and developed should be available in May 2018
New research project

The Engineering and Physical Sciences Research Council has provided funding (grant no. EP/N033213/1) for research work aimed at developing a design for safety capability maturity indicator tool for the construction sector.

The research is being undertaken by a coalition of the Universities the West of England and Loughborough in the UK and East Carolina University in the USA Industry partners contributing towards the research include Bam Construction Limited, the Health and Safety Executive, Heathrow Airport, ISG, Mott MacDonald, Nick Bell Risk Consultancy, GCP Architects and Safety in Design.

The research project started in October 2016 and will be completed in September 2018. It is anticipated that the tool will be ready for use by designers in May 2018.

\section{References}

Behm M (2005) Linking construction fatalities to the design for construction safety concept. Safety Science 43(8): 589-611.

Gibb A, Haslam R, Gyi D, Hide S and Duff R (2006) What causes accidents? Proceedings of the Institution of Civil Engineers - Civil Engineering 159(6): 46-50, http://dx.doi.org/10.1680/ cien.2006.159.6.46.

HMG (Her Majesty's Government) (2015) Health and Safety. The Construction (Design and Management) Regulations 2015. The Stationery Office, London, UK, Statutory Instrument 2015 No. 5

HSE (Health and Safety Executive) (2015a) Historical Picture - HISTINJ - Reported Injuries in Great Britain by Main Industry and Severity of Injury, 1974 to Latest Year. HSE, Bootle, UK. See http://www.hse.gov.uk/Statistics/tables/index. htm (accessed 12/07/2016).

HSE (2015b) Managing Health and Safety in Construction - CDM 2015 Guidance L153. HSE, Bootle, UK

Manu P, Ankrah N, Proverbs D and Suresh S (2014) The health and safety impact of construction project features. Engineering Construction and Architectural Management 21(1): 65-93. 